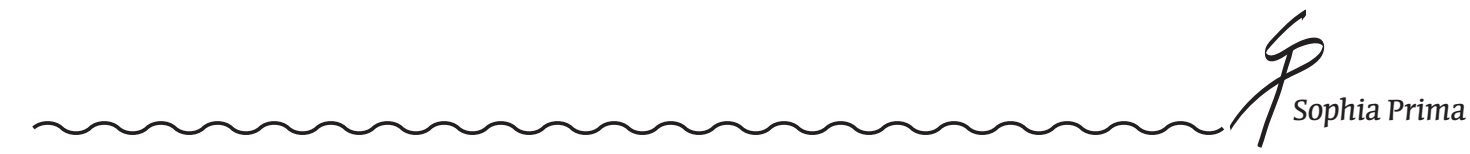

Philosophy. - T. 2. - Part 2. - L.: Ego, 1991. - P. 231235.

4. Zenkovsky VV Fundamentals of Christian Philosophy. - M .: Canon +, 1997. - 560 pp.

5. Zenkovsky VV On the image of God in man / Zenkovsky VV // Questions of Philosophy. 2003, No. 12, p. 147-161 (Reprint: Orthodox Thought, Issue 2. Paris, 1930, pp. 102-126).

6. Zenkovsky VV Principles of Orthodox Anthropology / Zenkovsky VV // Russian Religious Anthropology. T. 2. M., 1997, p. 431-466.

7. Zenkovsky V. The meaning of Orthodox culture / Sost., Predl. VL Shlenova - Moscow: Publishing House of Sretensky Monastery, 2007. 272 p. - (Spiritual legacy of the Russian abroad).

8. Spirkin AG Philosophy: Textbook. - 2nd ed. M .: Gardariki, 2002. - 736 p.

9. Jung K. G. The Man and His Symbols / Carl Gustav Jung. - M. B. C. K., 1996. - 378 c

Надійшла 22. 10. 2018

Бібліографічний опис для цитування :

Захаріна, М. I. Концепт «цілісної особистості» у філософському вченні В.В. Зеньковського / M.I. Захаріна // Sophia Prima: діалог вічного повернення. - 2019. - № 1. - С. 89-100.
УДК 16.330 .16

А.И. Зеленков, д. филос. н., профессор

\section{ПАРАДИГМАЛЬНОЕ ПРОСТРАНСТВО СОВРЕМЕННОГО ФИЛОСОФСКОГО ОБРАЗОВАНИЯ: СПЕЦИФИКА БЕЛОРУССКОГО ОПЫТА}

В статье рассматривается роль и социокультурный статус философии в современной культуре. При этом философия интерпретируется как академический дискурс и образовательный проект. Анализируется также белорусский опыт реформирования и трансформации философского образования в вузах Беларуси.

Ключевые слова: философия, образование, образовательные парадигмы, академическое сообщество.

Zelenkov A.I. Paradigm space of modern philosophical education: the specificity of the Belarusian experience.

The article is devoted to the role and socio-cultural status of philosophy in contemporary culture. At the same time, philosophy is interpreted as an academic discourse and an educational project. The Belarusian experience of reforming and transforming of philosophical education in Belarusian universities is also analyzed.

Keywords: philosophy, education, educational paradigms, academic community.

Актуальность темы исследования. Инвестиции в человеческий капитал оцениваются сегодня как определяющий фактор социально-экономического прогресса. Одним из основных направлений этих инвестиций всегда было и остается развитие гуманитарного образования. Любые попытки оспорить этот тезис чреваты повторением уже пройденных нами технократических ошибок и иллюзий, которые в современных условиях способны нанести серьезный ущерб перспективам 
развития постсоветских стран, их национальным интересам.

Появление образования как специфического типа деятельности и коммуникации знаменовало собой становление принципиально новых форм взаимодействия человека с окружающим его природным и социокультурным миром. Такое взаимодействие становилось возможным прежде всего через усвоение традиций и соответствующего культурного фона, характерного для того или иного типа общества. Собственно, именно в этот период и закладывается фундаментальное противоречие образования, состоящее в том, что оно органично соединяет в себе традиции и новации, нормы социального консерватизма и дух постоянного саморазвития личности, исследования и познания мира.

Сегодня преподавание философских дисциплин в высшей школе Республики Беларусь ориентировано на реализацию важнейших социальных функций. Прежде всего, это формирование духовно-нравственных основ жизнедеятельности личности, активная ее социализация на основе демократических и гуманистических ценностей. Одной из задач при этом является также обоснование перспективного сценария развития Беларуси как молодого суверенного государства, предполагающего органичное соединение интенсивной социальной модернизации, политической и национально-культурной стабильности в обществе.

В современной ситуации именно философия позволяет достаточно органично соединять рациональное содержание классических идей и подходов с новыми ценностями и инновационными программами. Философский разум всегда был ориентирован на внимательное и уважительное отношение к традиции, вместе с тем, ему также всегда была свойственна интенция на формирование творческого мышления, направленного на критичес- кую рефлексию по поводу основополагающих вопросов бытия.

Необходимо отметить, что современное состояние философии как научной дисциплины и учебного курса характеризуется высокой степенью проблематизации, очевидной размытостью парадигмальных основ и предметной неопределенностью. Эта тенденция релятивизации философской культуры приобрела осязаемые очертания в постклассической философии. В последней трети XX столетия она заметно усилилась и была дополнена самокритикой философского сознания в контексте идей и ценностей эпохи постмодерна.

Такая ситуация в сфере философии и философского образования не должна оцениваться негативно, как проявление своеобразной интеллектуальной аномалии. Скорее, наоборот, она вполне коррелирует с сущностной природой философии как уникальной формы духа и познания. Эту ее особенность неоднократно подчеркивали многие классики философии. В частности, К. Ясперс отмечал, что вопрос о том, что есть философия всегда вызывал споры и дискуссии и это необходимо связано с самой ее природой [1, с. 224-225].

Изложение основного материала. О динамике образовательных парадигм принято говорить в разных контекстах. Так, в исторической ретроспективе, начиная с эпохи Возрождения вплоть до сегодняшнего дня, можно зафиксировать, по меньшей мере, три базовых парадигмы: гуманитарную, политехническую и социокультурную [2, с. 250-253]. Предпосылки первой из них были заложены в греко-римской школе, а в эпоху Ренессанса они проявились в программной ориентации на изучение человека в его природных и духовно-нравственных воплощениях.

Основоположником политехнической парадигмы считают Александра 


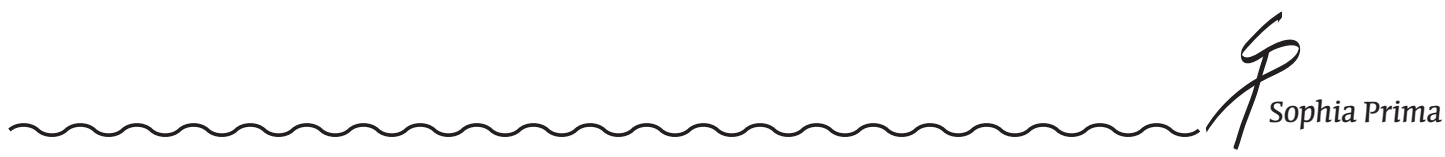

Гумбольдта, который обосновал необходимость инструментализации и профессионализации образования, связав его цели с освоением естественнонаучных и технических знаний.

В социокультурной парадигме, которая явилась своеобразной реакцией на издержки технократизма в образовании, акцент делается на многомерности образовательного процесса, который призван органично соединить ценности технологической эффективности и социокультурной приемлемости любых форм социальных инноваций.

Парадигмальное пространство современного философского образования также может быть рассмотрено через призму обозначенных выше исторических этапов развития образовательных практик. Однако при этом довольно сложно зафиксировать специфику философского образования с его интенцией на воспроизводство культурно-мировоззренческих и когнитивно-методологических оснований социальной деятельности и культуры.

Гораздо более продуктивной в этом отношении будет типология парадигмальных ориентаций, которая основывается на различных концептуальных стратегиях современного философствования (аналитическая, социально-критическая, экзистенциально-феноменологическая, герменевтическая, постмодернистская и др.).

Выбор одной из этих парадигмальных ориентаций (либо обоснованной их совокупности), как правило, осуществляется тогда, когда профессиональное сообщество интегрировано исследовательской традицией и продуктивно работающей «научной школой». В противном случае плюрализм парадигмальных оснований свидетельствует с одной стороны о своеобразном полицентризме и демократических ориентациях в процессе освоения классического и постклассиче- ского философского наследия. С другой о мировоззренческой неопределенности и релятивизме духовно-нравственных предпосылок философствования, что всегда свидетельствовало о кризисных симптомах в культуре и растерянности духа.

Программа конструктивного реформирования сложившейся практики философского образования в высшей школе должна органично сочетать принцип преемственности и установку на системно-инновационное использование информационных и методологических ресурсов современной философии. Но при этом необходимо со всей определенностью подчеркнуть, что любые попытки элиминировать философию как уникальную форму духовно-теоретического опыта, либо заменить ее какими-то иными типами социально-гуманитарного познания и образовательных практик неизбежно приведут к самым тяжелым и непредсказуемым последствиям.

Системно-инновационная методология, а также многолетний опыт преподавания философских дисциплин в Белорусском государственном университете, позволили предложить и обосновать комплексную модель чтения философских курсов для студентов, магистрантов и аспирантов. Конечно, эта модель в значительной степени учитывает специфику Белорусского государственного университета как университета классического типа. В ней нашли отражение академические традиции преподавания дисциплин социально-гуманитарного цикла, которые базируются на научно-исследовательских разработках и соответствующем кадровом их обеспечении.

Правда нельзя не сказать, что сегодня нет недостатка в критических и даже пессимистических оценках перспектив классического университетского образования. Все чаще провозглашается закат классического университета, переход его 
в фазу постисторического университета, в котором миссия либерального образования радикально утрачивается [3, с. 18].

В предлагаемой модели, исходя из целей и задач университетского образования, на первом его уровне в рамках базового курса «Философия» закладываются основы философско-мировоззренческой подготовки студента, и обеспечивается возможность освоения им мировой классической философской традиции в форме системно организованного знания.

На втором уровне, который, как правило, включает студентов, обучающихся по магистерским программам, предлагается курс «Философия в современном мире». Отличительной особенностью этого курса является его акцентированная направленность на проблематику и содержательные особенности современной философской мысли. Основная цель курса заключается в том, чтобы, опираясь на базовые знания по философии, которые уже имеются у студентов, познакомить их с наиболее значительными и актуальными идеями и концепциями современной философии.

Третий уровень философского образования должен быть ориентирован на задачи философско-методологического обеспечения научно-профессиональной деятельности аспирантов. Он предполагает чтение курса «Философия и методология науки», в котором основной акцент сделан на творческом осмыслении того сегмента философской проблематики, который имеет непосредственное отношение к вопросам, логики, методологии, социологии науки и образования.

Такая комплексная модель преподавания философских курсов в рамках университетской образовательной программы позволяет вполне эффективно использовать новейшие технологии обучения, а также находить перспективные развязки по ряду дискуссионных вопро- сов, касающихся преподавания философии. К ним, как правило, относят:

- проблему органичного сочленения в рамках университетского курса философии классического философского наследия и постклассических концепций и идей;

- проблему предметной определенности философии и четкое уяснение ее специфики по отношению к таким формообразованиям культуры, как наука, искусство, религия;

- проблему сочетания профессионально-академических стандартов в преподавании философии и интенций на коммуникативно-просветительскую деятельность, связанную с актуализацией образно-визуальных и суггестивно-риторических техник общения с аудиторией.

К сожалению, приходится констатировать, что современные унифицирующие технологии образования, в которых все более отчетливо доминируют формальные критерии в ущерб содержательным и мировоззренчески значимым параметрам академических курсов и программ, лишают возможности преподавателей философии в БГУ использовать в дальнейшем очевидные преимущества рассмотренной модели, которая на протяжении более чем 15 лет убедительно продемонстрировала свою конструктивность и высокий образовательный потенциал.

Первого сентября 2013 г. в соответствии с решением Министерства образования Республики Беларусь был санкционирован очередной этап реформирования образовательной сферы и, в частности, высшей школы. Весьма значительной трансформации была подвергнута система социально-гуманитарного образования. Большинство ее специальностей решено перевести на четырехлетний цикл обучения в рамках первой ступени высшего образования. Блок социально-гуманитарных дисциплин, которым тради- 
ционно и вполне обоснованно уделялось большое внимание в подготовке специалистов с высшим образованием, претерпел кардинальные изменения. Была предложена так называемая модульная система преподавания этих дисциплин, в рамках которой достаточно произвольно объединялись экономика и социология, политология и идеология современного белорусского государства, история, этика, эстетика и т.д. Весьма экзотический модуль был предложен и под названием «Философия». В нем отчетливо просматривается попытка механически сочленить искусственно урезанную программу предшествующего курса по философии в количестве 76 академических часов и некоторую часть тем из предшествующих курсов по педагогике и психологии. Данная сомнительная новация привела к тому, что студентам предлагается весьма эклектичная и зачастую поверхностная совокупность знаний о каждой из этих дисциплин без достижения их разумного синтеза. Еще большие проблемы возникают при этом в сфере технологий организации учебного процесса, что приводит к методическим и психологическим потерям, как для студентов, так и для преподавателей в проведении лекций, семинарских занятий и, в особенности, экзаменов и зачетов.

Конечно, в контексте тех процессов, которые происходят сегодня в экономической, социальной и образовательной сферах белорусского общества, идея своеобразной оптимизации и сокращения учебного времени, отводимого на изучение социально-гуманитарных дисциплин, должна быть оценена реалистически, как вполне современная и своевременная. Вместе с тем, конкретная форма ее реализации в виде предложенной модульной системы оказалась недостаточно продуманной и обоснованной. Об этом красноречиво свидетельствует уже появившийся опыт ее внедрения в учебный процесс во многих вузах республики. Это позволяет сделать вполне обоснованный вывод о том, что и в содержательном, и в организационно-методическом отношении она нуждается в дальнейшем обсуждении и серьезном совершенствовании.

Несколько иная акцентация проблем и содержательно-методических новаций становится необходимой, когда речь заходит о профессиональном философском образовании, ориентированном на воспроизводство кадровой структуры академического философского сообщества. Среди множества этих проблем важно указать на необходимость разработки и внедрения в учебный процесс дифференцированных программ обучения. В рамках, так называемой академической программы важно сохранить ориентацию на подготовку научно-педагогических кадров в целях воспроизводства профессиональной корпорации преподавателей философии и социально-гуманитарных наук в средней школе, средних специальных и высших учебных заведениях.

Вторая программа должна быть сориентирована на подготовку специалистов в области экспертно-аналитической деятельности. Это направление призвано актуализировать практико-ориентированную стратегию современного гуманитарного образования. Оно предполагает содержательную и философско-методологическую подготовку специалистов-консультантов, способных осуществлять системный анализ нестандартных социальных ситуаций, а также экологических и социокультурных вызовов в развитии современного общества.

Еще одним важным направлением развития современного философского образования является разработка и содержательно-методическое обоснование различных магистерских программ по основным направлениям философского знания. Причем они должны варьи- 
роваться не только по параметру их академической или практико-ориентированной направленности, но и по формам бюджетного либо внебюджетного финансирования. Современный мировой опыт и те реформы образования, которые осуществляются в России, в Украине и других странах СНГ, убедительно свидетельствуют о том, что престиж и реальный уровень университета в значительной степени зависят от количества и качества магистерских и докторских образовательных программ. В качестве наиболее актуальных и востребованных в современных условиях могут быть предложены следующие такие программы.

- «Философия и европейская цивилизация»

- «Философия и история белорусской культуры»

- «Философия языка и культура массовых коммуникаций»

- «Философия сознания и информационные технологии»

- «Философия и методология науки»

- «Философия образования»

- «Прикладная этика»

- «Философия и арт-бизнес»

- «Философия права»

- «Философия и современная эколо-

гия» и др.

Выводы и перспективы дальнейших исследований. Таким образом, философия была и призвана остаться не только неотъемлемым, но и системообразующим компонентом современного социально-гуманитарного образования. За многие столетия своего существования она разработала категориальный и методологический аппарат, не овладев которым, трудно рассчитывать на успешное решение современных научных, технологических и социальных проблем. Подлинно творческое, критическое и, в то же время, конструктивно-созидательное мышление вне и помимо философской традиции сформировать невозможно.
Об этом красноречиво свидетельствуют не только история, но и современный образовательный опыт ведущих университетов мира. Не является исключением в этом отношении и опты преподавания социально-гуманитарных дисциплин и, в особенности, философии в высшей школе Беларуси. Философия была и остается смыслообразующей инстанцией в процессе формирования интеллектуального капитала любой нации, стремящейся достойно и адекватно ответить на вызовы XXI столетия.

\section{Литература}

1. Ясперс, К. Введение в философию / К. Ясперс // Путь в философию: Антология. - М.; СПб, 2001. - 443 с.

2. Добреньков, В. И. Общество и образование / В. И. Добреньков, В. Я. Нечаев. - М.: ИНФРА-М, 2003. - 381 с.

3. Ридингс, Б. Университет в руинах / пер. с англ. А.М. Корбута; Гос. ун-т - Высшая школа экономики. - М.: Изд. дом Гос. ун-та - Высшей школы экономики, 2010. - 304 с.

\section{References}

1. Yaspers, K. Vvedenie v filosofiyu / K. Yaspers // Put v filosofiyu: Antologiya. - M.; SPb, 2001. $443 \mathrm{~s}$.

2. Dobrenkov, V. I. Obschestvo i obrazovanie / V. I. Dobrenkov, V. Ya. Nechaev. - M.: INFRA-M, 2003. - $381 \mathrm{~s}$

3. Ridings, B. Universitet $\mathrm{v}$ ruinah / per. $\mathrm{s}$ angl. A.M. Korbuta; Gos. un-t - Vyisshaya shkola ekonomiki. - M.: Izd. dom Gos. un-ta - Vyisshey shkolyi ekonomiki, 2010. - 304 s.

Надійшла 15.11.2018.

\section{Бібліографічний опис для цитування:}

Зеленков А.И. Парадигмальное пространство современного философского образования: специфика белорусского опыта / А.И. Зеленков // Sophia Prima: діалог вічного повернення 2019. - № 1. - C. 100-105. 